\title{
Keselamatan Dan Keamanan Laboratorium IPA
}

\author{
Meiske S. Sangia*, Adey Tanaumab* \\ aLab. Kimia Organik dan Bahan Alam, FMIPA, Unsrat, Manado \\ bLab. Fisika FMIPA Unsrat, Manado
}

\begin{tabular}{l} 
K A T A K U N C I \\
\hline Laboratorim \\
Keselamatan \\
Keamanan
\end{tabular}

\begin{abstract}
A B S T R A K
Laboratorium adalah tempat untuk melakukan percobaan maupun pelatihan yang memerlukan dorongan budaya keselamatan dan keamanan, sehingga lingkungan itu menjadi tempat yang aman untuk mengajar, belajar, dan bekerja. Pengelolaan keselamatan dan keamanan laboratorium IPA merupakan tanggung jawab bersama baik pengelola maupun pengguna, oleh karena itu setiap orang yang terlibat harus memiliki kesadaran dan merasa terpanggil untuk mengatur, memelihara, dan mengusahakan keselamatan kerja. Staf guru dan murid SMA merupakan salah satu pengguna fasilitas laboratorium yang perlu memahami pengelolaan tentang keselamatan dan keamanan laboratorium.Saat mengelolah bahan laboratorium, tidak semua resiko bisa ditiadakan.Keselamatan dan keamanan laboratorim dapat ditingkatkan melalui penilaian resiko berdasarkan informasi dan pengelolaan resiko yang cermat.Bahan kimia ramah lingkungan merupakan falsafah perancangan produk dan proses yang mengurangi atau meniadakan penggunaan dan terciptanya bahan berbahaya
\end{abstract}

K E Y W O R D S

Laboratory

Safety

Security

\begin{abstract}
A B S T R A C T
The laboratory is a place to conduct experiments as well as training that require the encouragement of safety and security culture, so that the environment becomes a safe place for teaching, learning, and working. The management of the safety and security in the science laboratory is a shared responsibility of both the manager and the user, therefore everyone involved must be aware and feel compelled to organize, maintain, and work for safety. Teacher staff and high school students are among the users of laboratory facilities who need to understand the management of laboratory safety and security. When managing laboratory materials, not all risks can be eliminated. The safety and security of the laboratory can be enhanced through risk-based risk information and risk assessment. Eco-friendly chemicals are the philosophy of designing products and processes that reduce or eliminate the use and creation of hazardous materials
\end{abstract}

TERSEDIA ONLINE

01 Februari 2018

1. Pendahuluan

Menurut PERMENPAN No. 3 tahun 2010 laboratorium adalah unit penunjang akademik pada lembaga pendidikan, berupa ruangan tertutup atau terbuka, bersifat permanen atau bergerak, dikelola secara sistematis untuk kegiatan pengujian, kalibrasi dan/atau produksi dalam skala terbatas, dengan menggunakan peralatan dan bahan berdasarkan metode keilmuan tertentu, dalam rangka pelaksanaan pendidikan, penelitian, dan/atau pengabdian kepada masyarakat.

Pengelolaan keselamatan dan keamanan Laboratorium kimia merupakan tanggung jawab bersama baik pengelola maupun pengguna, oleh karena itu setiap orang yang terlibat harus memiliki kesadaran dan merasa terpanggil untuk mengatur, memelihara, dan mengusahakan keselamatan kerja. Mengatur dan memelihara laboratorium merupakan upaya agar laboratorium selalu tetap berfungsi sebagaimana mestinya. Sedangkan upaya

*Corresponding author: Jurusan Kimia FMIPA UNSRAT, Jl. Kampus Unsrat, Manado, Indonesia 95115; Email address: meiskesangi@gmail.com

Published by FMIPA UNSRAT (2018) 
menjaga keselamatan kerja mencakup usaha untuk selalu mencegah kemungkinan terjadinya kecelakaan sewaktu bekerja di laboratorium dan penanganannya bila terjadi kecelakaan. Gurun, dan siswa merupakan salah satu pengguna fasilitas laboratorium yang perlu memahami pengetahuan yang cukup dalam hal pengelolaan tentang keselamatan dan keamanan laboratorium.

\section{Material dan Metode}

Metode yang digunakan dalam kegiatan IbM ini, adalah berupa kegiatan penyuluhantentang Keselamatan dan Keamanan Laboratorium IPA. Kegiatan dilaksanakan pada tanggal 27 Oktober 2017 di SMA Negeri 9 Binsus Manado.

\section{Hasil dan Pembahasan}

Bahan kimia ramah lingkungan untuk setiap Laboratorium

Dua belas prinsip bahan kimia ramah lingkungan dapat diterapkan ke semua laboratorium dan digunakan sebagai panduan untuk merancang dan melaksanakan eksperimen yang bijak.

1. Cegah limbah. sintesis Rancang kimia yang tidak menyisakan limbah apapun yang harus diolah atau dibersihkan.

2. Rancang bahan kimia dan produk yang lebih aman.

3. Rancang produk kimia yang sangat efektif, namun bahaya mengandung sedikit racun atau tidak sama sekali.

4. Rancang sintesis bahan kimia yang tidak terlalu berbahaya. Rancang sintesis untuk menggunakan dan menghasilkan zat dengan toksisitas rendah atau tidak beracun sama sekali bagi manusia dan lingkungan.

5. Gunakan bahan mentah yang dapat diperbarui. Hindari menghabiskan bahan mentah untuk industryyang dapat diperbarui dibuat dari produk pertanian atau limbah dari proses lainnya.Bahan mentah untuk industri yang tidak dapat diperbarui ditambang atau terbuat dari bahan bakar fosil (yaitu minyak tanah, gas alam, batu bara).

6. Gunakan katalis bukan reagen stoikiometrik. Katalis digunakan dalam jumlah kecil dan dapat melakukan reaksi tunggal beberapa kali. Katalis tersebut sebaiknya reagen stoikiometrik yang digunakan dalam jumlah berlebihan dan hanya bekerja sekali.

7. Hindari derivatif kimia.

8. Rancang sintesis sehingga produk akhir mengandung proporsi maksimal bahan awal. Hanya boleh ada sedikit, jika ada atom yang terbuang.

9. Gunakan pelarut dan kondisi reaksi yang lebih aman. Hindari menggunakan pelarut, bahan pemisah, atau bahan kimia tambahan lainnya. Jika bahan ini diperlukan, gunakan bahan kimia yang tidak berbahaya.
9. Tingkatkan efisiensi energi. Jalankan reaksi kimia pada suhu ruang dan tekanan bila memungkinkan

10. Rancang bahan kimia dan produk agar terurai menjadi zat yang tidak berbahaya setelah digunakan.

11. Analisis langsung untuk menghindari polusi.

12. Batasi potensi terjadinya kecelakaan. Rancang bahan kimia dan bentuknya (padat, cair, atau gas) untuk meminimalkan potensi terjadinya kecelakaan akibat bahan kimia termasuk ledakan, kebakaran, dan pelepasan ke lingkungan.

\section{Mencegah Limbah}

Beberapa strategi untuk mencegah limbah

1. Pikirkan cara penggunaan produk reaksi dan buat sejumlah keperluan saja.

2. Pikirkan biaya pembuatan dan penyimpanan bahan yang tidak dibutuhkan.

3. Cari cara untuk mengurangi jumlah langkah dalam eksperimen

4. Tingkatkan hasil

5. Daur ulang dan gunakan ulang bahan jika mungkin.

6. Koordinasikan pekerjaan dengan rekan kerja yang mungkin menggunakan beberapa bahan kimia yang sama.

7. Gunakan metode analitik paling sensitif yang ada saat melakukan analisis.

8. Pertimbangkan jumlah reagen, pelarut, dan bahan berbahaya yang digunakan dengan peralatan laboratorium otomatis saat membeli sistem baru.

9. Pisahkan limbah tidak berbahaya dan limbah berbahaya

10. Pertimbangkan penggunaan sistem pemurnian kolom untuk mendaur ulang pelarut yang digunakan.

\section{Menggunakan Pekerjaan Berskala Mikro}

1. Metode pengurangan bahaya yang berhasil adalah melakukan reaksi kimia dan prosedur laboratorium lainnya dalam skala yang lebih kacil atau berskala mikro.

2. Dalam bahan kimia berskala mikro, jumlah bahan yang digunakan dikurangi menjadi 25 hingga $100 \mathrm{mg}$ untuk zat padat dan 100 hingga $200 \mu \mathrm{L}$ untuk cairan, dibandingkan jumlah biasa, yaitu 10 hingga 50 g untuk zat padat atau 100 hingga $500 \mathrm{~mL}$ untuk cairan.

3. Penggunaan tingkat skala mikro menghemat berton-ton limbah atau jutaan dolar.

4. Disamping itu juga pekerjaan berskala mikro mengurangi bahaya kebakaran dan kemungkinan terjadinya kecelakaan serta tingkat keparahan kecelakaan yang memaparkan pegawai pada bahan kimia berbahaya.

Menggunakan Pelarut Dan Bahan Lainnya Yang Lebih Aman

1. Laboratorium lebih aman dan terjamin jika mereka mengganti dengan bahan kimia yang 
tidak berbahaya, atau kurang berbahaya bila memungkinkan.

2. Pertimbangkan jalur sintetik dan prosedur alternatif untuk melakukan campuran reaksi.

3. Ajukan pertanyaan saat memilih bahan reagen atau pelarut untuk prosedur eksperimen sebagai berikut:

4. Bisakah kita mengganti bahan ini dengan bahan lain yang memiliki potensi bahaya lebih kecil bagi pelaku eksperimen lainnya?

5. Bisakah kita mengganti bahan ini dengan bahan yang mengurangi atau meniadakan limbah berbahaya serta biaya pembuangannya?

Saat memilih pelarut organik, pertimbangkan beberapa faktor penting

- Hindari pelarut yang terdaftar sebagai toksin produktif, polutan udara berbahaya, atau karsinogen.

- Pilih pelarut dengan nilai ambang batas yang relatif tinggi.

- Pelarut pengganti yang paling baik memenuhi kondisi berikut. Pelarut juga memiliki sifat fisiokimia (misalnya titik didih, titik nyala, konstanta dielektrik) yang mirip dengan pelarut asli. Pertimbangkan manfaatnya bagi keselamatan, kesehatan dan lingkungan serta biayanya.

\section{Membeli Bahan Kimia}

1. Bagian dari pembelian bahan kimia adalah analisis masa pakai dan biayanya.

2. Biaya penanganan, dari segi manusia, keuangan dan biaya pembuangan harus diperhitungkan.

3. Tanpa analisis ini pesanan bisa jadi rangkap dan bahan kimia tak terpakai bisa jadi bagian signifikan dari limbah berbahaya di laboratorium.

4. Ada beberapa alasan untuk memesan bahan kimia sesuai kebutuhan dan dalam wadah kecil

5. Ukuran kemasan kecil utamanya mengurangi resiko kerusakan.

6. Wadah yang lebih kecil mengurangi resiko terjadinya kecelakaan dan pemaparan terhadap bahan berbahaya.

7. Inventaris ukuran tunggal mengurangi kebutuhan ruang penyimpanan.

8. Wadah kecil lebih cepat habis, sehingga mengurangi peluang terurainya senyawa reaktif.

9. Wadah besar sering kali harus dibagi. Ini memerlukan peralatan lain, seperti wadah pemindah yang lebih kecil, corong, pompa, dan label, serta peralatan kerja tambahan dan peralatan pelinding diri (PPE), untuk mengantisipasi bahaya yang ditimbulkan.

10. Biaya pembuangan wadah kecil dari bahan berbahaya yang tidak digunakan lebih kecil.

\section{Memesan Bahan Kimia}

Sistem pembelian terpusat harus mengontrol pemesanan jenis bahan tertentu, seperti bahan yang mudah terbakar di dalam wadah yang melebihi ukuran tertentu.Sebelum membeli bahan kimia, pegawai harus mengajukan beberapa pertanyaan :
Apakah bahan itu sudah tersedia dari laboratorium lain dalam lembaga itu atau ada kelebihan di gudang bahan kimia?

- Berapa jumlah minmal yang diperlukan untuk eksperimen?

- Berapa ukuran wadah yang paling sesuai di area tempat digunakannya atau disimpannya bahan tersebut?

- Tetapkan jumlah maksimal yang diperbolehkan untuk bahan kimia yang disimpan dalam laboratorium seperti bahan yang mudah terbakar atau gampang menyala.

- Bisakah bahan kimia tersebut dikelolah dengan aman setelah datang?

- Apakah memerlukan tempat penyimpanan khusus, seperti kotak kedap udara, lemari es, atau freezer?

- Apakah pegawai penerimaan perlu diberi tahu tentang pesanan itu dan diberi instruksi penerimaan khusus?

- Akankah peralatan khusus yang diperlukan siap saat pesanan tersebut datang?

Menerima Bahan Kimia

1. Batasi pengiriman bahan kimia ke area yang memiliki perlengkapan untuk menangani bahan kimia tersebut seperti tempat bongkar muat, ruang penerimaan, atau laboratorium.

2. Jangan mengirimkan bahan kimia ke kantor departemen yang tidak memiliki perlengkapan untuk menerima paket.

3. Jika pengiriman ke kantor serupa opsi satusatunya, tentukan lokasi terpisah dan jauh dari gangguan. Seperti meja atau rak untuk pengiriman bahan kimia.

4. Setelah bahan kimia datang segera beri tahu pegawai yang memesannya.

Langkah-langkah untuk memastikan penerimaan bahan Kimia

1. Latih pegawai ruang penerimaan, tempat bongkar muat, dan tata usaha untuk mengenali bahaya yang mungkin terkait dengan bahan kimia yang datang ke fasilitas. Mereka perlu tahu apa yang harus dilakukan jika terjadi masalah, seperti kemasan bocor atau terjadi tumpahan.

2. Lengkapi ruang penerimaan dengan peralatan yang sesuai untuk menerima bahan kimia. Siapkan rak, meja, atau area terkunci untuk kemasan untuk menghindari kerusakan akibat kendaraan ruang penerimaan.

3. Segera buka paket yang datang dan periksa untuk mengonfirmasi pesanan dan memastikan bahwa segel wadah dalam keadaan baik.

4. Simpan bahan kimia yang tidak dikemas dengan aman. Secara khusus segera buka kemasan dan simpan bahan kimia reaktif yang dikirimkan dalam wadah logam bersegel (seperti lithium aluminium hidrida, natrium peroksida fosfat)

5. Kirimkan bahan kimia dengan amam di dalam fasilitas. 
6. Jika pegawai pengiriman luar tidak menangani bahan sesuai standar fasilitas penerimaan, segera perbaiki atau cari pengangkut atau pemasok lain.

Inventaris dan Pelacakan Bahan kimia

- Inventaris adalah catatan, biasanya dalam bentuk basis data bahan kimia dalam laboratorium dan informasi penting tentang pengelolaannya.

- Semua laboratorium harus mencatat semua inventaris bahan kimia yang dimikinya secara akurat.

- Inventaris yang dikelolah dengan baik meliputi bahan kimia yang didapat dari sumber komersial dan yang dibuat di laboratorium, juga lokasi penyimpanan untuk setiap wadah masing-masing bahan kimia.

\section{Penyimpanan Bahan Kimia}

Panduan umum saat menyimpan bahan kimia dan peralatan bahan kimia :

1. Sediakan tempat penyimpanan khusus untuk masing-masing bahan kimia dan kembalikan bahan kimia ke tempat itu setelah digunakan.

2. Simpan bahan dan peralatan di lemari dan rak khusus penyimpanan.

3. Amankan rak dan unit penyimpanan lainnya. Pastikan rak memiliki bibir pembatas di bagian depan agar wadah tidak jatuh. Tempatkan wadah cairan pada baki logam atau plastik yang bisa menampung cairan bila wadah rusak. Tindakan ini utamanya penting di kawasan yang rawan gempa bumi atau kondisi cuaca ekstrem lainnya.

4. Hindari penyimpanan bahan kimia di atas bangku, kecuali bahan kimia yang sedang digunakan. Hindari jga penyimpanan bahan dan peralatan di atas lemari.

5. Jangan menyimpan bahan di rak yang tingginya lebih dari 5 kaki ( $\square \sim 1,5 \mathrm{~m}$ )

6. Hindari menyimpan bahan berat di bagian atas

7. Jaga agar pintu keluar, koridor, area di bawah meja atau bangku, serta area peralatan keadaan darurat tidak dijadikan tempat penyimpanan peralatan dan bahan.

8. Labeli semua wadah bahan kimia dengan tepat. Letakkan nama pengguna dan tanggal penerimaan pada semua bahan yang dibeli untuk membantu kontrol inventaris.

9. Hindari menyimpan bahan kimia pada tudung asap kimia, kecuali bahan kimia yang sedang digunakan.

Simpan racun atsiri (mudah menguap) atau bahan kimia pewangi pada lemari berventilasi. Jika bahan kimia tidak memerlukan lemari berventilasi, simpan di dalam lemari yang bisa ditutup atau rak yang memiliki bibir pembatas di bagian depan.

10. Simpan cairan yang mudah terbakar di lemari penyimpanan cairan yang mudah terbakar yang disetujui.
11. Jangan memaparkan bahan kimia yang disimpan ke panas atau sinar matahari langsung.

12. Simpan bahan kimia dalam kelompok-kelompok bahan yang sesuai secara terpisah yang disortir berdasarkan abjad.

13. Ikuti semua tindakan pencegahan terkait penyimpanan bahan kimia yang tidak sesuai

14. Berikan tanggung jawab untuk fasilitas penyimpanan dan tanggung jawab lainnya di atas kepada satu penanggung jawab utama dan satu orang cadangan. Kaji tanggung jawab ini minimal setiap tahun.

Penyimpanan Cairan Yang Mudah Terbakar dan Gampang Menyala:

1. Cairan yang gampang terbakar dan mudah menyala di laboratorium hanya boleh tersedia dalam jumlah terbatas.

2. Jumlah yang diperbolehkan tergantung pada sejumlah faktor :

- Konstruksi laboratorium

- Jumlah zona api dalam gedung

- Tingkat lantai tempat laboratorium berlokasi

- Sistem perlindungan api yang dibangun dalam laboratorium

- Adanya lemari penyimpanan cairan yang mudah terbakar atau kaleng keselamatan

- Jenis laboratorium

Panduan menyimpan Cairan Mudah Terbakar dan Gampang Menyala:

1. Jika tempatnya memungkinkan, simpan cairan yang gampang menyala dalam lemari penyimpanan bahan yang mudah terbakar.

2. Simpan cairan gampang menyala di dalam wadah aslinya (atau wadah lain yang disetujui) atau dalam kaleng keselamatan.

3. Simpan 55 galon ( 208 L) drum cairan yang mudah terbakar dan gampang menyala dalam ruang penyimpanan khusus untuk cairan yang mudah terbakar.

4. Jauhkan cairan yang mudah terbakar dan mudah menyala dari bahan oksidasi kuat, seperti asam nitrat atau kromat, permanganat, klorat, perklorat, dan peroksida

5. Jauhkan cairan yang mudah terbakar dan gampang menyala dari sumber penyulutan.

\section{Penyimpanan Zat yang Sangat Reaktif}

1. Pertimbangkan persyaratan penyimpanan setiap bahan kimia yang sangat reaktif sebelum membawanya ke dalam laboraturium.

2. Baca MSDS atau literatur lainnya mengambil mengambil keputusan tentang penyimpanan bahan kimia yang sangat reaktif.

3. Bawa bahan sejumlah yang diperlukan kedalam laboraturium untuk tujuan jangka pendek (hingga persediaan 6 bulan, tergantung pada bahannya).

4. Pastikan memberi labe, tanggal, dan mencatat dalam infentaris semua bahan yang sangat reaktif segera setelah bahan diterima.

5. Jangan membuka wadah bahan yang sangat reaktif yang telah melebihi tanggal kadaluarsa. 
Hubungi koordinator limbah berbahaya di lembaga anda untuk mendapatkan instruksi khusus.

6. Jangan membuka peroksida organik cair atau pembentuk peroksida jika ada kristal atau endapan. Hubungi CSSO Anda untuk mendapatkan instruksi khusus.

7. Untuk masing-masing bahan kimia yang sangat reaktif, tentukan tanggal pengkajian untukmengevaluasi kembali kebutuhan dan kondisi untuk membuang (atau mendaur ulang) bahan yang terurai dari waktu ke waktu.

8. Pisahkan bahan berikut :

9. Agen pengoksidasi dengan agen preduksi dan bahan mudah terbakar;

10. Bahan reduksi kuat dengan substrat yang mudah direduksi;

11. Senyawa piroforik dengan bahan yang mudah terbakar; dan

12. Asam perklorik dengan bahasa reduksi.

13. Simpan cairan yang sangat reaktif di baki yang cukup besar untuk menampung isi botol

14. Simpan peroksida organik cair pada suhu terendah yang mungkin sesuai dengan daya larut atau titik beku. Peroksida cair sangat sensitif selama perubahan fase. Ikuti panduan pabrik untuk penyimpanan bahan yang sangat berbahaya ini.

15. Lakukan inspeksi dan uji bahan kimia pembentuk peroksida secara periodik dan beri bahan label akuisisi dan tanggal kadaluwarsa.

16. Simpan bahan yang sangat sensitif atau simpan lebih banyak bahan eksplosif dalam kotak anti ledakan.

17. Batasi akses ke fasilitas penyimpanan.

\section{Penyimpanan Bahan yang Sangat Beracun}

Lakukan tindakan pencegahan berikut saat menyimpan karsinogen, toksin reproduktif, dan bahan kimia dengan toksisitas akut tinggi.

1. Simpan bahan kimia yang diketahui sangat beracun dalam penyimpanan berventilasi dalam perangkat pengaman sekunder yang resisten secara kimia dan anti pecah.

2. Jaga jumlah bahan pada tingkat kerja minimal.

3. Beri label area penyimpanan dengan tanda peringatan yang sesuai.

4. Pelihara inventaris untuk semua bahan kimia yang sangat beracun.

4. Kesimpulan

- Pengelolaan keselamatan dan keamanan laboratorium IPA merupakan tanggung jawab bersama baik pengelola maupun pengguna, oleh karena itu setiap orang yang terlibat harus memiliki kesadaran dan merasa terpanggil untuk mengatur, memelihara, dan mengusahakan keselamatan kerja.

- Guru, dan siswa merupakan salah satu pengguna fasilitas laboratorium yang perlu memiliki pengetahuan cukup tentang keselamatan dan keamanan laboratorium IPA

\section{Daftar Pustaka}

American Chemical Society, Devisi Kesehatan dan Keselamatan Kimia Membership.acs.org/c/chas/default. htm.

Aldrin E. Sweeney \& Jeffrey A. Paradis. (2003). Addressing the Professional Preparation of Future Science Teachers to Teach Hands - on Science : a Pilot Study of a Labora-tory Model. 80 (2), 171 - 173.

Bateman, S.T. dan Zeithami, P.C. (1990). Management Function and Strategy. Boston : Homewood.

Depdikbud. (1979). Pengelolaan Laboratorium Sekolah dan Manual Alat IPA. Jakarta : Direktorat Pendidikan Menengah Umum.

Hall, F.J. (1986). Experimental Chemistry. Massachusetts : D.C. Heath and Company.

International Union of Pure and Applied Chemistry, 2011. Keselamatan Dan Keamanan Laboratorium Kimia: Panduan Pengelolaan Bahan Kimia dengan Bijak. www.nas.edu/bcst

National Research Council. (2010. Keselamatan dan Keamanan Laboratorium Kimia: A Guide to Prudent Chemical Management. Washington, DC: The National Academies Press,

Sudaryanto, Indrawati, dan Endang Kowara. (1998). Pengelolaan laboratorium IPA dan Instalasi Listrik. Jakarta : Depdikbud.

The General Safety Committee. (1954). Guide for Safety in the Chemical Laboratory. New York : D. Van Nostrand Company. Inc.

National Research Council. Promoting Chemical Laboratory Safety and Security in Developing Countries. Washington, DC: The National Academies Press, 2010.7: 335-345 